\title{
Surface passivation of silicon solar cells using plasma-enhanced chemical-vapour-deposited SiN films and thin thermal $\mathrm{SiO}_{2}$ /plasma $\mathrm{SiN}$ stacks
}

\author{
Jan Schmidt ${ }^{1}$, Mark Kerr and Andrés Cuevas \\ Centre for Sustainable Energy Systems, Department of Engineering, Faculty of Engineering \\ and Information Technology, Australian National University, Canberra ACT 0200, Australia \\ E-mail: Jan.Schmidt@ipe.uni-stuttgart.de
}

Received 18 September 2000, accepted for publication 13 December 2000

\begin{abstract}
Two different techniques for the electronic surface passivation of silicon solar cells, the plasma-enhanced chemical vapour deposition of silicon nitride $(\mathrm{SiN})$ and the fabrication of thin thermal silicon oxide/plasma SiN stack structures, are investigated. It is demonstrated that, despite their low thermal budget, both techniques are capable of giving an outstanding surface passivation quality on the low-resistivity $(\sim 1 \Omega \mathrm{cm})$ p-Si base as well as on $\mathrm{n}^{+}$-diffused solar cell emitters with the oxide/nitride stacks showing a much better thermal stability. Both techniques are then applied to fabricate frontand rear-passivated silicon solar cells. Open-circuit voltages in the vicinity of $670 \mathrm{mV}$ are obtained with both passivation techniques on float-zone single-crystalline silicon wafers, demonstrating the outstanding surface passivation quality of the applied passivation schemes on real devices. All-SiN passivated multicrystalline silicon solar cells achieve an open-circuit voltage of $655 \mathrm{mV}$, which is amongst the highest open-circuit voltages attained on this kind of substrate material. The high open-circuit voltage of the multicrystalline silicon solar cells results not only from the excellent degree of surface passivation but also from the ability of the cell fabrication to maintain a relatively high bulk lifetime ( $>20 \mu$ s) due to the low thermal budget of the surface passivation process.
\end{abstract}

\section{Introduction}

Effective silicon surface passivation techniques with a low thermal budget are highly desirable in solar cell processing technology. This is because the standard high-temperature surface passivation schemes, based on oxidizing the silicon surface at temperatures around $1000^{\circ} \mathrm{C}$, are well known to degrade the bulk carrier lifetime of most multicrystalline $(\mathrm{mc})$ silicon materials and are furthermore undesirable from cost and throughput considerations. In recent years, the surface passivation of silicon solar cells by means of plasma-enhanced chemical-vapour-deposited (PECVD) silicon nitride $(\mathrm{SiN})$ films fabricated at low temperature $\left(\leqslant 400^{\circ} \mathrm{C}\right)$ has proved to give an outstanding degree of

1 Present address: Institute of Physical Electronics, University of Stuttgart, Pfaffenwaldring 47, D-70569 Stuttgart, Germany. electronic surface passivation [1-7] with the best passivation quality obtained for very silicon-rich SiN films [5,6]. In addition to the favourable electronic properties, SiN films also act as a very effective antireflection coating on silicon [1,2]. The unique combination of excellent electronic and optical properties of the silicon-rich SiN films have led to record bifacial silicon solar cells with front efficiencies in excess of $20 \%$ and rear efficiencies exceeding 18\% [8]. However, in spite of their success, there are several problems associated with the high silicon content of these SiN films, like poor etchability, hindering the local opening of the $\mathrm{SiN}$ by means of chemical etching as routinely used in the fabrication of high-efficiency solar cells, and high absorption in the UV range of the sun spectrum, reducing the short-circuit current of the cell. In the first part of this study, we show that the above-mentioned disadvantages of silicon-rich $\mathrm{SiN}$ can 
be overcome by using nearly stoichiometric well passivating $\mathrm{SiN}$.

Two more general problems of the surface passivation with $\mathrm{SiN}$ films are that (i) the surface passivation quality strongly deteriorates during long-term annealing treatments and (ii) the plasma deposition parameters have to be very thoroughly optimized in order to obtain the best possible surface passivation quality. The second part of the paper investigates an elegant and simple way of avoiding these difficulties by introducing a thin thermally grown silicon dioxide $\left(\mathrm{SiO}_{2}\right)$ layer between the silicon nitride and the silicon.

Finally, the investigated passivation schemes are applied to front and rear-passivated silicon solar cell structures in order to demonstrate their potential for applications in high-efficiency silicon solar cells.

\section{Passivation of low-resistivity p-Si surfaces}

\subsection{Silicon nitride}

The SiN films were deposited by means of direct PECVD in a commercially available parallel-plate reactor (Oxford Plasma Technology, Plasmalab 80+) using ammonia and a silane/nitrogen mixture (4.5\% silane, $95.5 \%$ nitrogen) as process gases. Figure 1 shows a schematic diagram of the reactor. In former studies [5-7] usually undiluted silane gas was used, which is, in contrast to the much less hazardous silane/nitrogen mixture, highly inflammable if it comes in contact with air. To minimize the plasma damage of the silicon surface during the deposition, a high excitation frequency (13.56 MHz) was applied. As has been shown by Lauinger et al [6], the ion bombardment in a parallel-plate PECVD setup, and hence the plasma damage, can be largely suppressed using an excitation frequency well above the plasma frequency of about $4 \mathrm{MHz}$. The high-frequency parallel-plate approach has even been proved to be capable of giving the same very high degree of SiN surface passivation as the microwavedownstream remote PECVD approach, where the plasma is excited in a microwave cavity outside the deposition chamber and the silicon wafer surface is not in direct contact with the plasma during deposition.

In order to optimize the surface passivation quality of the SiN films, lifetime test structures were fabricated. These samples are $1 \Omega \mathrm{cm}$ float-zone (FZ) p-Si wafers $(400 \mu \mathrm{m}$ thick) with $60 \mathrm{~nm}$ of $\mathrm{SiN}$ deposited on both surfaces [9]. The effective carrier lifetime $\tau_{\text {eff }}$ of the samples was measured using a contactless photoconductance decay system (Sinton Consulting, WCT100) [10]. In this system, the sample is inductively coupled to a calibrated rf circuit whose output voltage is directly correlated to the conductance of the sample. During each measurement, the sample is exposed to a short light pulse generated by means of a flash lamp. After termination of the light pulse, the time-dependent output signal of the rf circuit is recorded with an oscilloscope (Tektronix TDS 320) and converted into the photoconductance. In order to maximize the signal-to-noise ratio, typically hundreds of transients are averaged. Using an appropriate mobility model and assuming a spatially uniform injection profile throughout the wafer, the excess carrier concentration $\Delta n$ is calculated from the photoconductance signal. The effective lifetime is

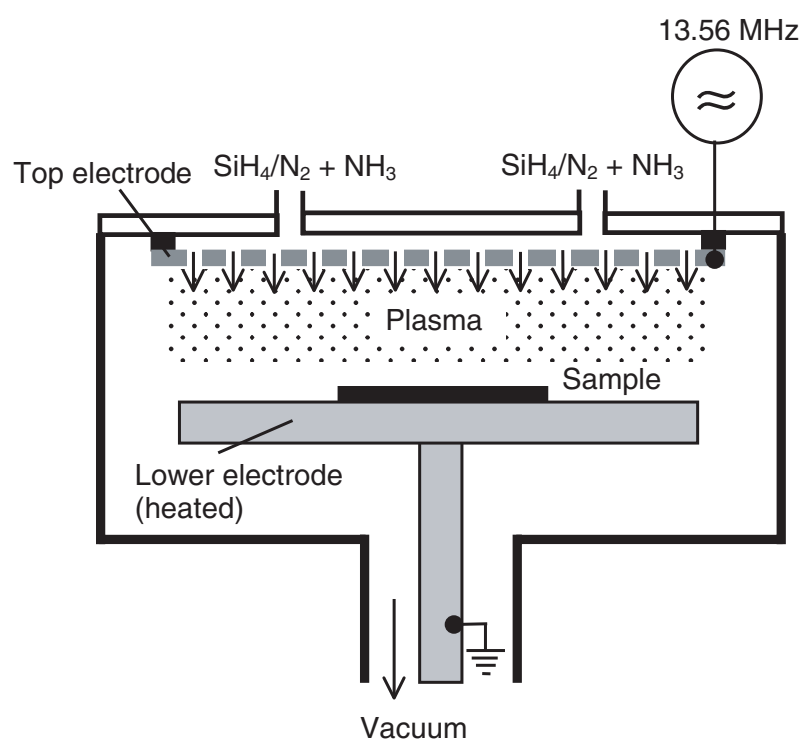

Figure 1. Schematic diagram of the parallel-plate PECVD reactor. The sample is placed on the lower, grounded electrode. The gas inlet is via the powered 'showerhead' top electrode.

then determined using the expression $\tau_{\text {eff }}=-\Delta n /(\mathrm{d} \Delta n / \mathrm{d} t)$. As generally $\tau_{\text {eff }}$ is a function of $\Delta n$, all $\tau_{\text {eff }}$ values reported in this paper were measured at a fixed injection level of $10^{15} \mathrm{~cm}^{-3}$.

The PECVD parameters varied were the substrate temperature, the total gas pressure, the plasma power, the gas flows and the silane/nitrogen-to-ammonia gas flow ratio $\left[\mathrm{SiH}_{4}: \mathrm{N}_{2}\right] /\left[\mathrm{NH}_{3}\right]$. Figure 2 shows the impact of the two most important parameters: the deposition temperature and the gas flow ratio. Also included in figure 2 is the refractive index $n$ of some $\mathrm{SiN}$ films at a wavelength of $630 \mathrm{~nm}$, as determined from reflectance measurements. The $\mathrm{NH}_{3}$ flow was fixed at $50 \mathrm{sccm}$, the pressure at 0.2 Torr and the plasma power at $100 \mathrm{~W}$ during this experiment. While the plasma power had only a relatively weak impact on the surface passivation quality within the investigated parameter range, an increase of $\tau_{\text {eff }}$ with decreasing gas pressure was found (see figure 3 ). It is important to note that the same dependence of $\tau_{\text {eff }}$ on the gas flow ratio as shown in figure 2 was also found for an $\mathrm{NH}_{3}$ flow of $100 \mathrm{sccm}$, indicating that the important $\mathrm{SiN}$ deposition parameter is indeed the ratio of the gas flows. As can be seen from figure 2, there exists an optimal gas flow ratio, which lies between 4 and 7 , depending on the deposition temperature. The optimum gas flow ratio as well as the maximum of $\tau_{\text {eff }}$ increases with the deposition temperature. For the highest deposition temperature used in this study $\left(400^{\circ} \mathrm{C}\right)$, a $\tau_{\text {eff }}$ value of $900 \mu$ s was obtained for the optimum gas flow ratio. This corresponds to a very low effective surface recombination velocity (SRV), $<10 \mathrm{~cm} \mathrm{~s}^{-1}[9,11]$. Hence, the surface passivation quality of the SiN films optimized in this paper is equivalent to the best $\mathrm{SiN}$ films reported to date $[5,6]$. The main difference of our optimized SiN films over those investigated in $[5,6]$ is that they are close to stoichiometry (indicated by a refractive index of 1.9) rather than very rich in silicon (refractive index $>2.2$ ). As a consequence of this, our optimized SiN films do not absorb any UV photons of the sun spectrum [9] and their etch rates in buffered hydrofluoric acid are considerably higher (by about a factor of six) compared to 


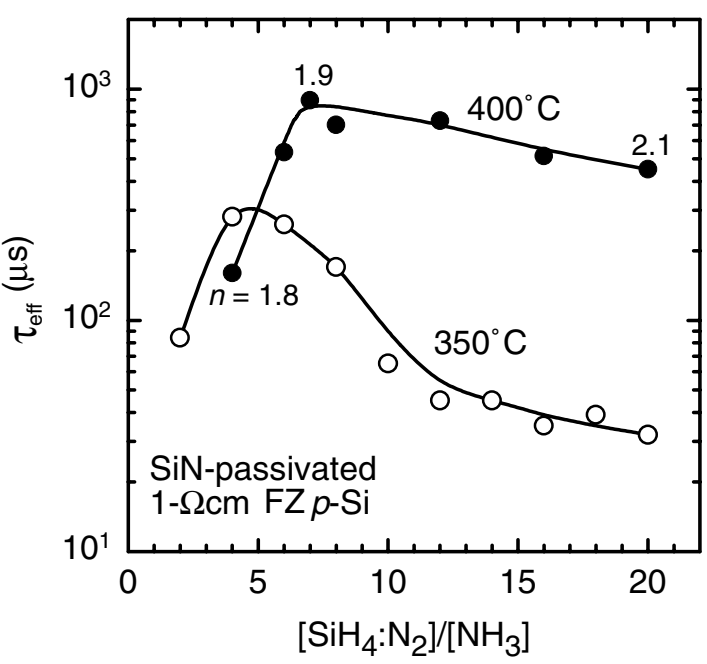

Figure 2. Impact of the $\mathrm{SiN}$ deposition temperature and the silane/nitrogen-to-ammonia gas flow ratio on the effective carrier lifetime $\tau_{\text {eff }} n$ is the refractive index of the silicon nitride at a wavelength of $630 \mathrm{~nm}$.

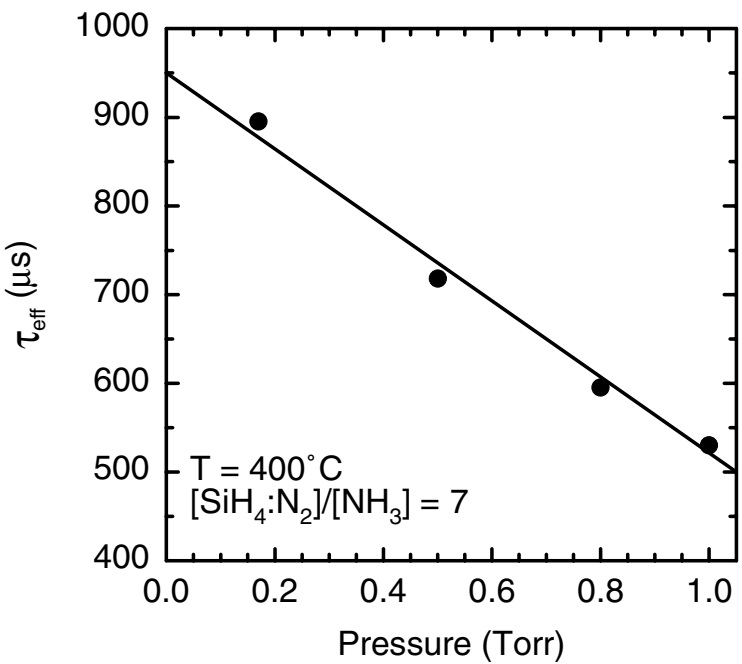

Figure 3. Impact of the gas pressure on $\tau_{\text {eff }}$. Fixed parameters are the substrate temperature $\left(400^{\circ} \mathrm{C}\right)$, the gas composition $\left(\left[\mathrm{SiH}_{4}: \mathrm{N}_{2}\right] /\left[\mathrm{NH}_{3}\right]=7\right)$ and the power $(100 \mathrm{~W})$.

that of the silicon-rich films, making it possible to apply the standard procedure of photolithography and chemical etching to pattern the nitride. More advanced technologies have to be used for patterning silicon-rich $\mathrm{SiN}$ films [12,13]. The fundamentally different passivation behaviour of our $\mathrm{SiN}$ films (i.e. excellent electronic surface passivation for stoichiometric films) seems to be due to the addition of nitrogen to the process gases of silane and ammonia. The deposition rate of our optimized $\mathrm{SiN}$ films $\left(\sim 30 \mathrm{~nm} \mathrm{~min}{ }^{-1}\right)$ is comparable to that obtained using undiluted silane gas instead of a silane/nitrogen mixture.

The same optimization experiment has also been performed on $0.3 \Omega \mathrm{cm} \mathrm{FZ} \mathrm{p-Si}$, giving the same set of optimal deposition parameters. On these $300 \mu \mathrm{m}$ thick wafers, the optimized SiN films produced an effective lifetime of $190 \mu \mathrm{s}$, corresponding to an effective $S R V$ of $15 \mathrm{~cm} \mathrm{~s}^{-1}$. With regard to the fact that it becomes increasingly difficult to electronically passivate a p-Si surface with increasing doping concentration, this is a remarkably good result on such a highly doped material.

Despite the mentioned advantages of stoichiometric over silicon-rich SiN films, it should be emphasized that for many applications the well passivating silicon-rich $\mathrm{SiN}$ films are clearly preferable over the stoichiometric SiN films (e.g. as surface-passivating antireflection coating in encapsulated silicon solar cells [14]). In this context we would like to refer to the fact that our silicon-rich $\mathrm{SiN}$ films with a refractive index of 2.1 (see figure 2) still provide a lifetime of $450 \mu \mathrm{s}$ on $1 \Omega \mathrm{cm}$ p-Si wafers. This implies a sufficiently high degree of surface passivation (SRV $30 \mathrm{~cm} \mathrm{~s}^{-1}$ ) for high-efficiency solar cell applications [1]

\subsection{Thermal stability of the SiN passivation}

A general problem of the surface passivation by means of plasma SiN films is the relatively poor stability of the passivation quality during annealing treatments [15]. As the annealing behaviour of the surface passivation quality can be of considerable importance for a potential solar cell fabrication process, we have investigated the thermal stability of our optimized SiN films. Figure 4 shows the annealing behaviour of the optimized $\mathrm{SiN}$ passivation in comparison with a thermally grown high-temperature $\left(1050^{\circ} \mathrm{C}\right)$ silicon dioxide. The annealing was performed at $400{ }^{\circ} \mathrm{C}$ in forming gas $(5 \%$ $\mathrm{H}_{2}, 95 \% \mathrm{~N}_{2}$ ). This treatment is routinely used in solar cell processing for sintering the metal contacts. As can be seen from figure 4, the behaviours of the plasma $\mathrm{SiN}$ and the thermal $\mathrm{SiO}_{2}$ passivation are very different. The effective lifetime of the oxidized Si wafer increases during the first $50 \mathrm{~min}$ of the anneal and then saturates on a constant lifetime level. We attribute this effect to the hydrogenation of silicon dangling bonds a the $\mathrm{Si} / \mathrm{SiO}_{2}$ interface. For the $\mathrm{SiN}$-passivated wafer, the lifetime increases during the first $30 \mathrm{~min}$ of the anneal and, for longer annealing times, decreases with time following an exponential law. The same behaviour was observed for SiNpassivated $\mathrm{Si}$ wafers annealed in a nitrogen ambient instead of forming gas. From this comparison we conclude that, in contrast to the thermally oxidized silicon surface, the forming gas is not actively involved in the annealing process. Hence, the large reservoir of hydrogen in the silicon nitride $(\sim 15$ 20 at.\%) seems to be responsible for the initial increase of $\tau_{\text {eff }}$ with the annealing time. Within the bulk of the SiN film the hydrogen is present in the form of $\mathrm{Si}-\mathrm{H}$ and $\mathrm{N}-\mathrm{H}$ bonds, where the weaker $\mathrm{N}-\mathrm{H}$ bonds break up more easily than the more stable $\mathrm{Si}-\mathrm{H}$ bonds during annealing. The hydrogen set free from the $\mathrm{N}-\mathrm{H}$ bonds passivates silicon dangling bonds within the bulk of the $\mathrm{SiN}$ as well as at the $\mathrm{Si} / \mathrm{SiN}$ interface, thereby decreasing the effective SRV at the $\mathrm{Si} / \mathrm{SiN}$ interface and, consequently, increasing $\tau_{\text {eff }}$. As two kinds of $\mathrm{N}-\mathrm{H}$ bonds with very different bonding energies exist in SiN [16], mainly the weak type of $\mathrm{N}-\mathrm{H}$ bond breaks up and the density of the strong $\mathrm{N}-\mathrm{H}$ bonds remains unchanged. As soon as all weak $\mathrm{N}-\mathrm{H}$ bonds are dissociated, the dominant dissociation process becomes the breaking up of $\mathrm{Si}-\mathrm{H}$ bonds. During this process, new silicon dangling bonds are created at the $\mathrm{Si} / \mathrm{SiN}$ interface and $\tau_{\text {eff }}$ degrades.

In order to improve the understanding of the physical mechanism behind the thermal degradation, annealing 


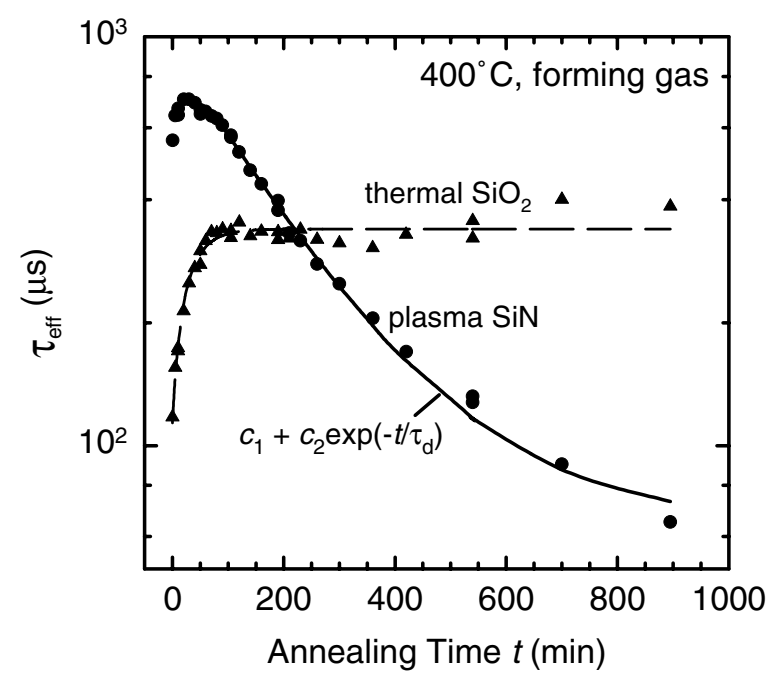

Figure 4. Annealing behaviour of the effective lifetime of two $1 \Omega \mathrm{cm} \mathrm{FZ} \mathrm{p-Si} \mathrm{wafers} \mathrm{passivated} \mathrm{by} \mathrm{plasma} \mathrm{SiN}$ and thermally grown $\mathrm{SiO}_{2}$.

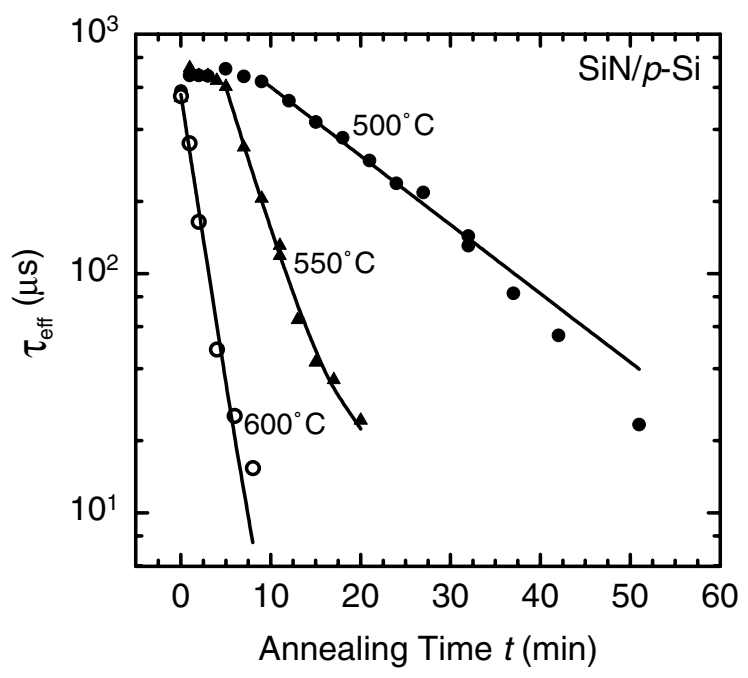

Figure 5. Thermal degradation of the effective lifetime of $\mathrm{SiN}$-passivated $1 \Omega \mathrm{cm} \mathrm{FZ} \mathrm{p-Si} \mathrm{wafers} \mathrm{at} \mathrm{different} \mathrm{temperatures.}$

experiments were performed at different temperatures (see figure 5). The time constant $\tau_{\mathrm{d}}$ of the degradation process was determined as a function of the annealing temperature $T$ by fitting a single-exponential function $c_{1}+c_{2} \exp \left(-t / \tau_{\mathrm{d}}\right)$ to the measurements. As can be seen from figure $5, \tau_{\mathrm{d}}$ is strongly temperature dependent: while $\tau_{\mathrm{d}}$ is $190 \mathrm{~min}$ at $400^{\circ} \mathrm{C}, \tau_{\mathrm{d}}$ decreases to only $2 \mathrm{~min}$ at $600^{\circ} \mathrm{C}$. Figure 6 shows an Arrhenius plot of the degradation time constant. From this plot, the activation energy of the degradation process was determined to be $E_{\mathrm{a}} \approx 1.2 \mathrm{eV}$. This value is in good agreement with the activation energy reported by Lauinger et al [15]. However, the fact that it is about twice as large as the activation energy reported for the dissociation of the $\mathrm{Si}-\mathrm{H}$ bond [16] indicates that the mechanism responsible for the thermal degradation of the SiN passivation quality is probably more complicated than previously assumed. Further experimental investigations seem to be necessary to reveal the detailed mechanism of the thermal degradation process.

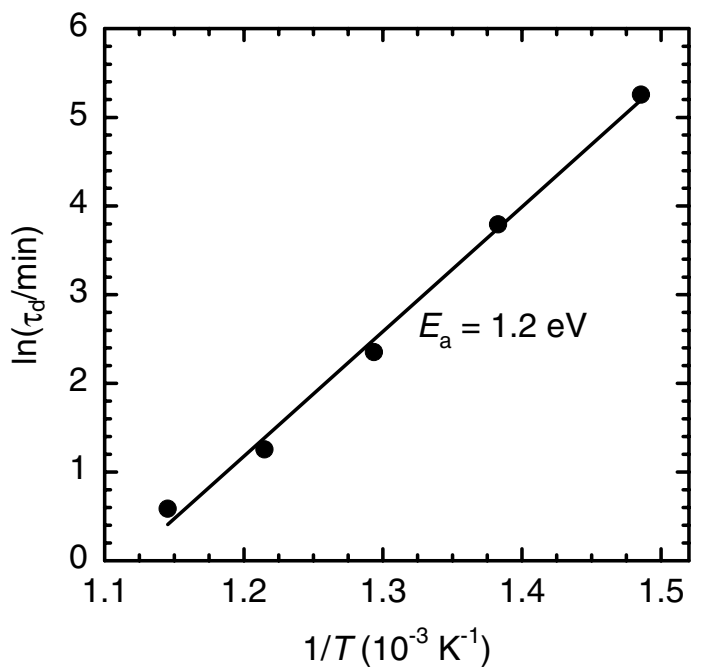

Figure 6. Arrhenius plot of the degradation time constant $\tau_{\mathrm{d}}$.

\subsection{Double layers of thermal $\mathrm{SiO}_{2}$ and plasma $\mathrm{SiN}$}

Figure 7 shows the measured effective lifetimes of several thermally oxidized $1 \Omega \mathrm{cm}$ FZ p-Si wafers with various $\mathrm{SiO}_{2}$ thicknesses before (open squares) and after (closed squares) the deposition of $60 \mathrm{~nm}$ thick SiN films on top of the $\mathrm{SiO}_{2}$. The oxides were grown in an oxygen/trichloroethylene ambient using a conventional quartz furnace. The $\mathrm{SiO}_{2}$ thickness was varied using different growth temperatures $\left(900\right.$ and $1000^{\circ} \mathrm{C}$ ) and oxidation times (5-63 min). As can be seen from figure 7, the as-grown oxides give a very poor surface passivation with $\tau_{\text {eff }}$ varying between 5 and $8 \mu \mathrm{s}$. An enormous increase in lifetime is observed after the deposition of SiN layers on top of the $\mathrm{SiO}_{2}$. In agreement with experimental results of Rohatgi et al $[17,18]$ obtained on very similar test structures, these oxide/nitride stacks provide an excellent degree of surface passivation, as indicated by measured $\tau_{\text {eff }}$ values between 1 and $2 \mathrm{~ms}$ (see figure 7). However, in contrast to the results reported in $[17,18]$, in our experiments no high-temperature annealing of the stacks was necessary after the SiN deposition to attain this excellent electronic surface passivation. The reason for this might be that we used another oxidation technique than that used in $[17,18]$, where rapid thermal processing was applied. It is also worth noting that, in our study, we could not establish any correlation between the thickness of the oxide layers and the passivation quality of the $\mathrm{SiO}_{2} / \mathrm{SiN}$ stacks. Hence, very thin oxide layers ( $\sim 10 \mathrm{~nm}$ thick) should be used preferentially.

The surface passivation provided by a thin oxide/nitride stack is slightly more effective than the best single-layer SiN passivation. However, even more important is the strongly improved thermal stability of the surface passivation by the thin oxide/nitride stacks compared to the single-layer $\mathrm{SiN}$ passivation (see figure 8). This makes the stack passivation scheme particularly well suited for solar cell fabrication processes, where the surface passivation has to withstand a higher temperature (e.g. during the firing of screen-printed metal contacts). The only possible drawback of the stack passivation scheme is the requirement of a high-temperature step (the oxidation), which, in the case of mc silicon substrates, could cause a degradation of the bulk lifetime. However, due to the low overall thermal budget of the fast thermal 


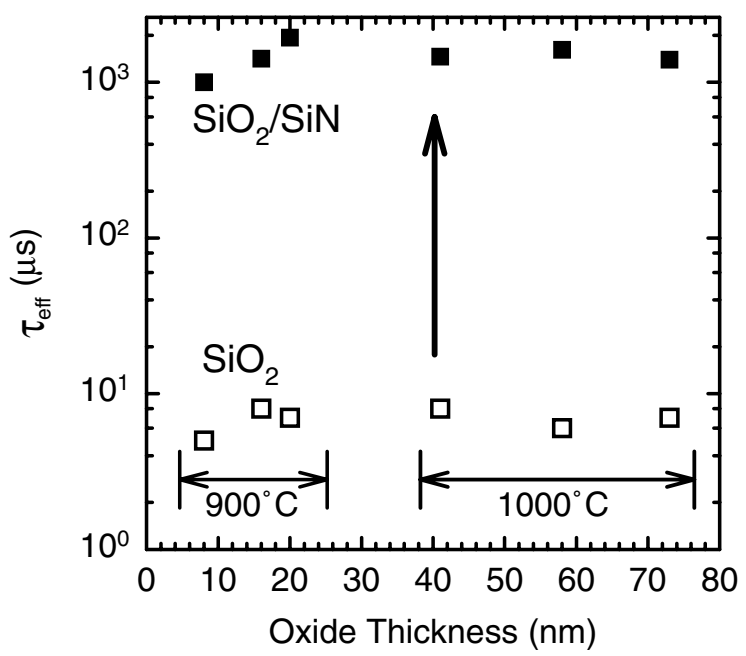

Figure 7. Effective lifetimes of several thermally oxidized $1 \Omega \mathrm{cm}$ FZ p-Si wafers before (open squares) and after (closed squares) the deposition of $60 \mathrm{~nm}$ thick $\mathrm{SiN}$ layers. The $\mathrm{SiO}_{2}$ was grown at 900 and $1000{ }^{\circ} \mathrm{C}$. The oxidation time was varied from 5 to $63 \mathrm{~min}$.

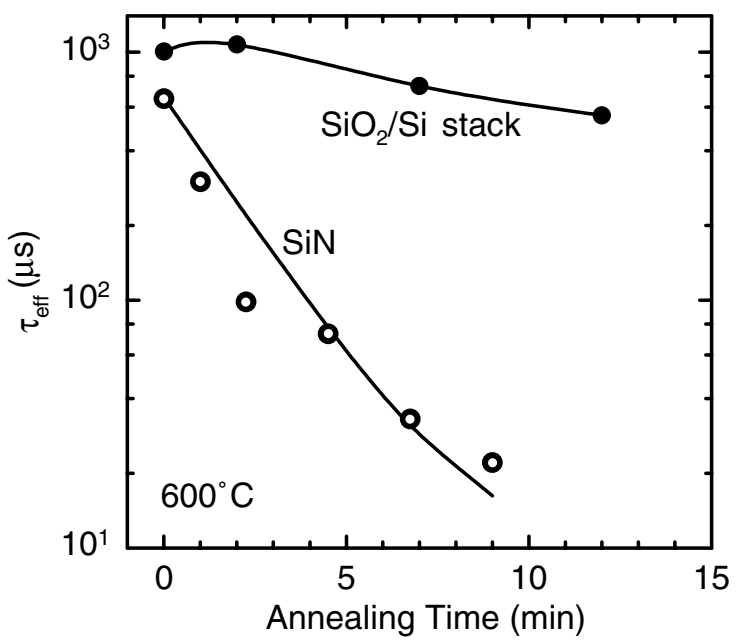

Figure 8. Annealing behaviour of the effective lifetime of two $1 \Omega \mathrm{cm} \mathrm{FZ} \mathrm{p-Si} \mathrm{wafers} \mathrm{passivated} \mathrm{by} \mathrm{a} \mathrm{single-layer} \mathrm{SiN} \mathrm{film} \mathrm{and} \mathrm{an}$ $\mathrm{SiO}_{2} / \mathrm{SiN}$ stack. The $\mathrm{SiO}_{2}$ was grown at $900{ }^{\circ} \mathrm{C}$ for $5 \mathrm{~min}$ and is $8 \mathrm{~nm}$ thick. The thickness of the SiN layers is about $60 \mathrm{~nm}$.

oxidation process required to grow thin layers $(\sim 10 \mathrm{~nm})$ of $\mathrm{SiO}_{2}$ compared to a standard high-temperature oxidation, bulk lifetime degradation should be negligible in most cases.

Interestingly, we find that for the $\mathrm{SiO}_{2} / \mathrm{SiN}$ double layer a thorough optimization of the PECVD parameters, as necessary in the case of the single-layer $\mathrm{SiN}$ deposition, is not required and that the degree of surface passivation is independent of most deposition parameters (except for the deposition temperature, which was fixed at $400{ }^{\circ} \mathrm{C}$ in our experiments).

The physical explanation for the excellent passivation quality of the $\mathrm{SiO}_{2} / \mathrm{SiN}$ stacks lies probably in the high quality of the $\mathrm{Si} / \mathrm{SiO}_{2}$ interface, which is grown into the silicon crystal at a relatively high temperature, and the subsequent very effective hydrogenation of dangling bond interface states during the SiN deposition.

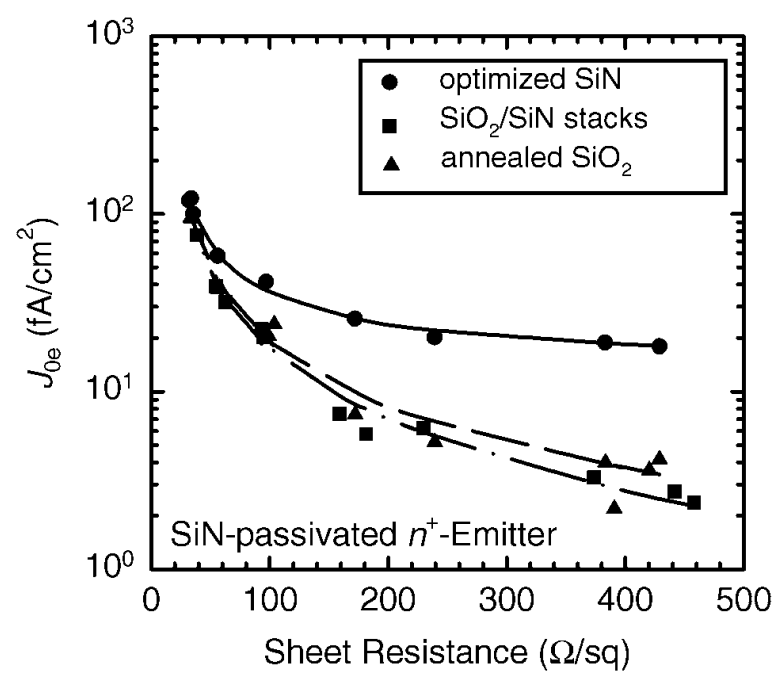

Figure 9. Emitter saturation current density $J_{0 \mathrm{e}}$ as a function of the emitter sheet resistance for three different surface passivation schemes.

\section{Passivation of $\mathbf{n}^{+}$-diffused solar cell emitters}

The optimization of the PECVD parameters on phosphorusdiffused solar cell emitters was performed on high-resistivity $(50 \Omega \mathrm{cm}) \mathrm{FZ}$ silicon wafers with symmetrical emitter structure $\left(\mathrm{n}^{+} \mathrm{pn}^{+}\right)$. The $\mathrm{n}^{+}$-emitters were diffused at temperatures between 840 and $925^{\circ} \mathrm{C}$ using liquid $\mathrm{POCl}_{3}$ as dopant source. The emitter saturation current density $J_{0 \mathrm{e}}$ was determined from the slope of the injection-level-dependent effective carrier lifetime [19,20]. The optimized SiN deposition parameters were very similar to those found on the non-diffused $\mathrm{p}-\mathrm{Si}$ wafers, with the substrate temperature and the gas flow ratio as the most influential parameters (see figure 2) [19]

Figure 9 shows the measured $J_{0 \mathrm{e}}$ values as a function of the emitter sheet resistance for the optimized single-layer $\mathrm{SiN}$ passivation, the $\mathrm{SiO}_{2} / \mathrm{SiN}$ stacks and an aluminium-annealed ('alnealed') high-temperature $\mathrm{SiO}_{2}$. The alnealed $\mathrm{SiO}_{2}$ is used as reference since this passivation scheme is known to provide an optimum degree of electronic surface passivation on crystalline silicon [21]. The alneal was performed by first evaporating an aluminum capping layer on both surfaces of the oxidized wafers. Subsequently, the samples were annealed at $400{ }^{\circ} \mathrm{C}$ for $30 \mathrm{~min}$ in forming gas and finally the Al layers were removed by means of chemical etching. By this method, large amounts of atomic hydrogen are generated within the oxide layer, effectively passivating silicon dangling bonds at the $\mathrm{Si} / \mathrm{SiO}_{2}$ interface. The hydrogen is believed to be generated by the reaction of $\mathrm{Al}$ with residual water molecules within the oxide [1]. Interestingly, it was found that an alnealing treatment has virtually no impact on the passivation quality of SiN-passivated silicon surfaces [13]. This finding is consistent with the large hydrogen content of these films.

As can be seen from figure 9, the optimized $\mathrm{SiN}$ gives very low emitter saturation current densities between 20 and $100 \mathrm{fA} \mathrm{cm}^{-2}$ [19]. However, the oxide/nitride stack structure is again superior to the single-layer $\mathrm{SiN}$ passivation as demonstrated by $J_{0 \mathrm{e}}$ values as low as $\sim 3 \mathrm{fA} \mathrm{cm}^{-2}$ for a sheet resistance of $\sim 450 \Omega / \mathrm{sq}$. The stack structure is hence even comparable to the best passivation scheme known to date, the 
Surface passivation of silicon solar cells

Table 1. Measured 1 sun parameters of planar PERC solar cells fabricated on FZ and mc-Si substrates ( $V_{\text {oc }}$, open-circuit voltage; FF, fill factor; $J_{\mathrm{sc}}$, short-circuit current density; $\eta$, energy conversion efficiency) [22,23]. The nominal cell area is $4 \mathrm{~cm}^{2}$.

\begin{tabular}{|c|c|c|c|c|c|c|}
\hline Cell & $1^{\mathrm{a}}$ & 2 & 3 & 4 & 5 & $6^{\mathrm{a}}$ \\
\hline Silicon wafer & $\mathrm{FZ}, 300 \mu \mathrm{m}$ & $\mathrm{FZ}, 300 \mu \mathrm{m}$ & $\mathrm{FZ}, 300 \mu \mathrm{m}$ & $\mathrm{FZ}, 300 \mu \mathrm{m}$ & $\mathrm{FZ}, 300 \mu \mathrm{m}$ & $\mathrm{mc}, 200 \mu \mathrm{m}$ \\
\hline Resistivity $(\Omega \mathrm{cm})$ & 0.3 & 0.7 & 0.3 & 0.3 & 0.3 & 0.2 \\
\hline Front passivation & $\mathrm{SiN}$ & $\mathrm{SiN}$ & $\mathrm{SiN}$ & $\mathrm{SiO}_{2} / \mathrm{SiN}$ & $\mathrm{SiO}_{2} / \mathrm{SiN}$ & $\mathrm{SiN}$ \\
\hline Rear passivation & $\mathrm{SiN}$ & $\mathrm{SiN}$ & alnealed $\mathrm{SiO}_{2}$ & alnealed $\mathrm{SiO}_{2}$ & $\mathrm{SiO}_{2} / \mathrm{SiN}$ & $\mathrm{SiN}$ \\
\hline$V_{\mathrm{oc}}(\mathrm{mV})$ & 667.3 & 668 & 661 & 673 & 665 & 655.4 \\
\hline$J_{\mathrm{sc}}\left(\mathrm{mA} \mathrm{cm}^{-2}\right)$ & 33.1 & 33.6 & 33.5 & 33.6 & 32.0 & 31.0 \\
\hline $\mathrm{FF}(\%)$ & 80.7 & 77.8 & 80.0 & 81.0 & 76.3 & 78.9 \\
\hline$\eta(\%)$ & 17.8 & 17.5 & 17.7 & 18.3 & 16.2 & 16.1 \\
\hline
\end{tabular}

${ }^{a}$ Independently confirmed at Sandia National Laboratories.

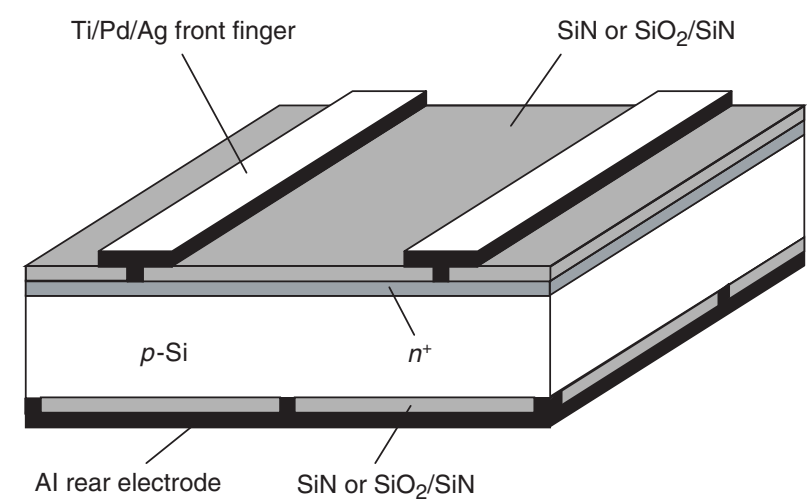

Figure 10. Schematic illustration of the simplified PERC solar cell structure.

alnealed high-temperature $\mathrm{SiO}_{2}$. However, it should be noted that for typical solar cell emitter sheet resistances $(<150 \Omega /$ sq $)$ the variations between the investigated passivation methods are very small and all three techniques provide a good passivation quality. For a comprehensive analysis of our emitters, the interested reader is referred to [20].

\section{Application to silicon solar cells}

In order to demonstrate the potential of the investigated surface passivation methods for high-efficiency silicon solar cells, simplified passivated emitter and rear cells (PERCs) were fabricated (see figure 10) on FZ p-Si substrates as well as on Eurosolare mc silicon wafers. For the sake of simplicity, these cells have a non-textured front and a single-diffused emitter (with the sheet resistance lying between 100 and $130 \Omega / \mathrm{sq})$. The patterning of the passivation layers was performed by photolithography and chemical etching and the metal contacts were evaporated $(\mathrm{Ti} / \mathrm{Pd} / \mathrm{Ag}$ at the front, $\mathrm{Al}$ at the rear). Processing details have been published in a separate paper [22]. The metallization fractions were $2 \%$ at the front (including metal fingers and bus bar) and $4 \%$ at the pointcontacted rear. Table 1 summarizes the results of the best cells $[22,23]$.

As the open-circuit voltage $V_{\mathrm{oc}}$ is the most sensitive solar cell parameter with respect to the overall recombination in a solar cell, we focus our discussion on this particular parameter. The all-SiN passivated FZ cells 1 and 2 have a remarkably high $V_{\text {oc }}$ of 667 and $668 \mathrm{mV}$, respectively, confirming the excellent front and rear surface passivation provided by the SiN films. For comparison, previous all-SiN passivated cells with $\mathrm{n}^{+}$-diffused emitters had attained opencircuit voltages of $649 \mathrm{mV}$ [8] for a bifacial solar cell and, more recently, $660 \mathrm{mV}$ [12] for a PERC cell with random pyramid texture. The highest $V_{\text {oc }}$ shown in table $1(673 \mathrm{mV})$ was obtained for cell 4 with an $\mathrm{SiO}_{2} / \mathrm{SiN}$-passivated emitter and an alnealed $\mathrm{SiO}_{2}$ at the rear. The comparison with cell 3 (which has a $V_{\text {oc }}$ of only $661 \mathrm{mV}$ ) verifies that the oxide/nitride double layer passivation is indeed more efficient on $\mathrm{n}^{+}$-diffused emitters than the single-layer SiN passivation. In cell 5, the oxide/nitride stack was used for front and rear passivation. This cell has a reduced $V_{\mathrm{oc}}$ of $665 \mathrm{mV}$ compared with cell 4 . However, since this cell is partly shunted, as indicated by the relatively poor fill factor of $76.3 \%$, the reduction in $V_{\text {oc }}$ cannot just be attributed to a poorer surface passivation. In fact, the detailed analysis reveals that the surface passivation quality seems to be comparable for cells 4 and 5 .

Also shown in table 1 are the results obtained for an all$\mathrm{SiN}$ passivated mc-Si solar cell (cell 6). The cell was fabricated on a $0.2 \Omega \mathrm{cm}$ p-type mc-Si wafer made by Eurosolare. The open-circuit voltage of $655 \mathrm{mV}$ obtained for this cell is amongst the best $V_{\mathrm{oc}}$ values reported for mc silicon solar cells [24-26]. The high $V_{\text {oc }}$ results not only from the excellent degree of surface passivation but also from the ability of the cell fabrication process to maintain a relatively high bulk lifetime ( $>20 \mu \mathrm{s}$ ). A strong bulk lifetime degradation of the same mc-Si material was observed during standard high-temperature oxidation. This result shows the potential of the investigated $\mathrm{SiN}$ surface passivation for mc-Si solar cells.

\section{Conclusions}

The electronic surface passivation of the front and the rear of silicon solar cells by means of plasma SiN films and thin thermal $\mathrm{SiO}_{2}$ /plasma $\mathrm{SiN}$ double layers was investigated. Despite the low thermal budget of these techniques, very low effective SRVs $<10 \mathrm{~cm} \mathrm{~s}^{-1}$ were attained for both passivation techniques on low-resistivity $\mathrm{p}$-Si surfaces and emitter saturation current densities below $100 \mathrm{fA} \mathrm{cm}^{-2}$ on $\mathrm{n}^{+}$diffused solar cell emitters with the double layers showing a slightly better performance. The thermal stability of both passivation schemes was compared and it was found that the $\mathrm{SiO}_{2} / \mathrm{SiN}$ passivation shows a strongly improved stability during annealing compared with the single-layer $\mathrm{SiN}$ films. Another important advantage of the stack structure was found to be that a careful optimization of the plasma deposition parameters, as is inevitable in the case of the single-layer 
SiN passivation, is not necessary. A clear disadvantage of the $\mathrm{SiO}_{2} / \mathrm{SiN}$ stacks over the $\mathrm{SiN}$ passivation is the higher thermal budget of the double-layer passivation scheme, which might lead to a degradation of the bulk carrier lifetime in certain mc silicon materials. The application of both passivation techniques to simplified PERC solar cells demonstrated opencircuit voltages around $670 \mathrm{mV}$ on FZ silicon wafers. A $V_{\mathrm{oc}}$ of $655 \mathrm{mV}$ was obtained for an all-SiN passivated mc silicon solar cell. The cell results verify the well passivating properties of the investigated passivation schemes on real devices and demonstrate their applicability to high-efficiency solar cell structures.

\section{Acknowledgments}

The authors would like to thank $\mathrm{C}$ Jagadish and $\mathrm{H}$ Tan for making it possible to use the PECVD reactor at the Electronic Materials Engineering Department of the ANU. The technical assistance of C Samundsett and J Cotsell is gratefully acknowledged. The mc silicon substrates were kindly provided by F Ferrazza of Eurosolare SpA. Many thanks go to D S Ruby of Sandia National Laboratories and $\mathrm{K}$ Emery of NREL for providing the cell data under standard testing conditions. This paper has been supported by funding from the Australian Research Council. One of the authors (JS) gratefully acknowledges the support of a Feodor Lynen Fellowship by the German Alexander von Humboldt Foundation.

\section{References}

[1] Aberle A G 1999 Crystalline Silicon Solar Cells-Advanced Surface Passivation and Analysis (Rhodes: Bloxham and Chambers)

[2] Aberle A G and Hezel R 1997 Prog. Photovolt. 529

[3] Leguijt C, Lölgen P, Eikelboom J A, Weeber A W, Schuurmans F M, Sinke W C, Alkemade P F A, Sarro P M, Maree C H M and Verhoef L A 1996 Solar Energy Mater. Solar Cells 40297

[4] Agnihotri O P, Jain S C, Poortmans J, Szlufcik J, Beaucarne G, Nijs J and Mertens R 2000 Semicond. Sci. Technol. 15 R29
[5] Schmidt J, Lauinger T, Aberle A G and Hezel R 1996 Proc. 25th IEEE Photovoltaic Specialists Conf. (Washington, DC) $\mathrm{p} 413$

[6] Lauinger T, Aberle A G and Hezel R 1997 Proc. 14th European Photovoltaic Solar Energy Conf. (Barcelona) (Bedford: Stephens) p 853

[7] Lenkeit B, Lauinger T, Aberle A G and Hezel R 1998 Proc. 2nd World Conf. on Photovoltaic Solar Energy Conversion (Vienna) (Ispra: European Commission) p 1434

[8] Hübner A, Aberle A G and Hezel R 1997 Proc. 14th European Photovoltaic Solar Energy Conf. (Barcelona) (Bedford: Stephens) p 92

[9] Schmidt J and Kerr M 1999 Technical Digest 11th Photovoltaic Science and Engineering Conf. (Sapporo) (Kyoto: Tanaka) p 581

[10] Sinton R A and Cuevas A 1996 Appl. Phys. Lett. 692510

[11] Schmidt J and Kerr M 2001 Solar Energy Mater. Solar Cells 65585

[12] Preu R, Glunz S W, Schäfer S, Lüdemann R, Wettling W and Pfleging W 2000 Proc. 16th European Photovoltaic Solar Energy Conf. (Glasgow) at press

[13] Dauwe S, Metz A and Hezel R 2000 Proc. 16th European Photovoltaic Solar Energy Conf. (Glasgow) at press

[14] Nagel H, Aberle A G and Hezel R 1999 Prog. Photovolt. 7245

[15] Lauinger T, Moschner J, Aberle A G and Hezel R 1998 J. Vac. Sci. Technol. A 16530

[16] Maeda M and Itsumi M 1998 J. Appl. Phys. 845243

[17] Rohatgi A, Narasimha S and Ruby D S 1998 Proc. 2nd World Conf. on Photovoltaic Solar Energy Conversion (Vienna) (Ispra: European Commission) p 1566

[18] Rohatgi A, Doshi P, Moschner J, Lauinger T, Aberle A G and Ruby D S 2000 IEEE Trans. Electron Devices 47987

[19] Kerr M, Schmidt J and Cuevas A 2000 Proc. 16th European Photovoltaic Solar Energy Conf. (Glasgow) at press

[20] Kerr M, Schmidt J, Cuevas A and Bultman J H 2001 J. Appl. Phys. at press

[21] Eades W D and Swanson R M 1985 J. Appl. Phys. 584267

[22] Kerr M, Schmidt J and Cuevas A 2000 Prog. Photovolt. 8529

[23] Kerr M, Schmidt J, Samundsett C and Cuevas A 2000 Proc. 16th European Photovoltaic Solar Energy Conf. (Glasgow) at press

[24] Stocks M, Blakers A and Cuevas A 1997 Proc. 14th European Photovoltaic Solar Energy Conf. (Barcelona) (Bedford: Stephens) p 766

[25] Cuevas A, Stocks M, Macdonald D, Kerr M and Samundsett C 1999 IEEE Trans. Electron Devices 462026

[26] Zhao J, Wang A, Campbell P and Green M A 1999 IEEE Trans. Electron Devices 461978 